Natural Hazards and Earth System Sciences (2003) 3: 103-114

(C) European Geosciences Union 2003

\title{
A space-time rainfall generator for highly convective Mediterranean rainstorms
}

\author{
S. Salsón and R. Garcia-Bartual \\ Hydraulic Engineering and Environment Department, Politechnical University of Valencia, Spain
}

Received: 4 February 2002 - Revised: 12 June 2002 - Accepted: 19 June 2002

\begin{abstract}
Distributed hydrological models require fine resolution rainfall inputs, enhancing the practical interest of space-time rainfall models, capable of generating through numerical simulation realistic space-time rainfall intensity fields. Among different mathematical approaches, those based on point processes and built upon a convenient analytical description of the raincell as the fundamental unit, have shown to be particularly suitable and well adapted when extreme rainfall events of convective nature are considered. Starting from previous formulations, some analytical refinements have been considered, allowing practical generation of space-time rainfall intensity fields for that type of rainstorm events. Special attention is placed on the analytical description of the spatial and temporal evolution of the rainfall intensities produced by the raincells. After deriving the necessary analytical results, the seven parameters of the model have been estimated by the method of moments, for each of the 30 selected rainfall events in the Jucar River Basin (ValenciaSpain) - period 1991 to 2000, using 5-min aggregated rainfall data series from an automatic raingauge network.
\end{abstract}

\section{Introduction}

The important recent advances in distributed hydrological models have significantly increased the practical need for space-time rainfall models. These new operational tools supported by GIS technology provide a better understanding of the rainfall-runoff processes at the basin scale. Through the distributed modeling approach, it can be investigated, among others, what the effect of spatial and temporal variability of rainfall intensity on the resulting basin hydrograph is.

But rainfall is never measured continuously in space and time, and thus, rainfall models representing the physical and statistical characteristics of the observed rainfall fields are an interesting alternative for practical purposes. On the other

Correspondence to: R. Garcia-Bartual

(rgarciab@hma.upv.es) hand, this approach provides a practical way to generate synthetic events representing future realistic flood situations, i.e. inflow hydrographs to a reservoir produced by a extreme rainfall event, which are required to evaluate certain operational criteria of the reservoir and dam. This paper presents a conceptual multidimensional model of non-stationary spacetime rainfall at the catchment scale due to a single storm event. The model belongs to a well known family of stochastic models constructed around the original formulation by Waymire et al. (1984), and continued in a series of combined developments during the following years (Rodriguez-Iturbe and Eagleson, 1987; Sivapalan and Wood, 1987; Jacobs et al., 1988; Islam et al., 1988; Valdés et al., 1990; Bartolini and Valdés, 1994). This kind of approaches assume that a precipitation area of a given scale has one or more smaller scales embedded, which involve more intense precipitation, as a result of the physical features of atmospheric dynamics (Orlanski, 1975). The smallest characteristic features or identifiable patterns inside the storm are locally intense precipitation areas in the vicinity of well defined storm cells centers, with a decreasing rainfall intensity as distance from the cell center increases. According to Waymire et al. (1984), the order of magnitud of these raincells ranges from 10 to $50 \mathrm{~km}$ in horizontal spatial scale, with time duration scales below the hour. In recent applications, such conceptual approaches built upon the raincell as basic building-block of the storm structure have served as the basis to analyse the influence of rainfall inputs on the hydrological response (Luyckx et al., 1998; Northrop, 1998; Willems, 1999, 2001). In all these models, a conceptual representation of the essential features observed in a variety of storm types is considered. Basically, the storm is assumed to consist of a conceptual hierarchy of scales. In such a structure, the smallest scale is represented by rain cells, which are the fundamental units for the model construction. It is at that cell-scale where the highest rainfall intensities are reached, while rainfall intensities decrease as the spatial scale increases. The occurrence of rain cells varies in both space and time, their birth mechanism is governed by a space-time point process. The analytical description of this 
point process, together with the analytical form given to the intensities produced by the cells, always play a crucial role in the formulation of the cited models.

It should be remarked here that in all cases, the probability distributions of all the components in such models are selected to assure mathematical tractability, with analytical derivation of first and second order moments of the instantaneous rainfall intensity process in space and time $\xi(t, z)$, representing rainfall intensity on the ground at time $t$ and spatial co-ordinates $z$.

These analytical results are then used for parameter estimation by means of the widely used method of moments, as a first step for the practical use of the models. The maximum likelihood method becomes in most cases mathematically intractable for this type of models.

The parameter estimation requirements lead to an inherent compromise between analytical complexity and the need of a realistic description of the typical structural features observed in measured rainfall fields. And it is this analytical limitation that explains certain properties of the models, chosen largely as a mathematical convenience to facilitate the analytical evaluation of the process's theoretical moments.

Among the models quoted, the one proposed by Rodriguez-Iturbe and Eagleson (1987) (hereafter referred to as RE) represents a particularly interesting and balanced formulation, providing an attractive scheme for applied purposes. In that model, individual storm events are characterized as a three dimensional, space-time random process. Cells are born in space following a two dimensional Poisson process of parameter $\lambda$. They arrive in time ( $\tau$ relative to the storm onset) according to an exponential distribution $f(\tau)=\beta \cdot \exp (-\beta \cdot \tau), \beta$ being a parameter. Rainfall intensity generated by a cell is described as:

$g(a, r)=i_{0} \cdot \exp (-\alpha \cdot a) \cdot \exp \left[-r^{2} / 2 D^{2}\right]$,

where $a$ and $r$ represent relative time and distance from the time-space origin of the cell, and $i_{0}, \alpha$ and $D$ are parameters of the model. The resultant rainfall intensity field can be obtained analytically by adding in space and time the contributions of all cells born before the instant under consideration.

This formulation has already been applied to model extreme events of convective nature in the Mediterranean regions of Spain by Lázaro and Garcia Bartual (1991). The type of rainfall events considered, typically occurring during months of September, October and November, exhibit clearly some of the essential features of the RE model, and there is in this case a strong empirical evidence in favor of a rainfall structure built upon convective cells as the basic unit. On the other hand, and due to the extreme hydrologic regime characteristic of the region, event oriented models of this type (rainfall models of the internal structure of the storm) are far more suitable than continuous-time models (also dealing with the interarrival structure of rainfall), specially when applications related to flood forecasting and control are considered.

The basic assumptions of the RE model are: (1) nonstationary, (2) statistical spatial homogeneity (isotropic cor- relation structure), (3) Poisson distribution of cells in space, (4) quadratic exponential attenuation of intensity with increasing distance from the cell center, and exponentially distributed cell center intensity, (5) time of birth of cells exponentially distributed, (6) exponential time-evolution of raincell intensity.

All these assumptions are largely discussed in the work by Jacobs et al. (1988). Concerning the last two assumptions, it is clear, as stated in their research, that they largely facilitate the analytical evaluation of the process's theoretical moments, but cannot strictly be considered physically based hypotheses. In particular, there are strong reasons to refine assumption (6), proposing instead some other function better representing the typical cell life evolution, starting with a low intensity and increasing gradually with time until the peak is reached, and then gradually tailing off. Temporal patterns with a delayed peak are more realistic (Hershfield, 1984) and have also been used in stochastic modeling of precipitation (Garcia-Bartual and Marco, 1990).

The statistical analysis of 30 storms in the Jucar River Basin (Spain) that occurred between 1991 and 2000, has also revealed that other analytical assumptions (rather than the exponential) for the temporal birth of cells, better reproduce the internal evolution of cumulative rainfall during the course of the storm.

The outlined considerations motivated this research, and yielded to a new multidimensional model that incorporates certain analytical refinements, preserving the general structure of the original RE model. More precisely, a gamma-type function is introduced to model temporal shape of the cell, representing a cell with a rapid increase, marked peak section and gradual decline of intensity, as used in the stochastic temporal model by Garcia-Bartual et al. (1990), while an Erlang distribution is used to describe birth of cells during the course of the storm. As a result of these two modifications, a new model is derived, of which all required analytical expressions for parameter estimation are obtained. The derived theoretical normalized mean function of the new model presents an intermediate inflexion point, showing a pattern that is closer to other common normalized temporal patterns used in applied hydrology (U.S. Department of Agriculture Soil Conservation Service, 1986).

We illustrate that the new model can be tuned successfully, in a way that is reasonably straightforward, although the operational rain gauge network provides a limited spatial information about rainfall intensity fields. More reliable parameter estimates requires finer spatial information, from a denser network or, preferable, using data derived from radar imagery.

\section{Analytical development}

The main objective of this research is the characterization of the individual storm events as a three-dimensional spacetime random process. The principal variable of the process is the rainfall intensity $\xi(t, z)$, occurring at the point with spa- 


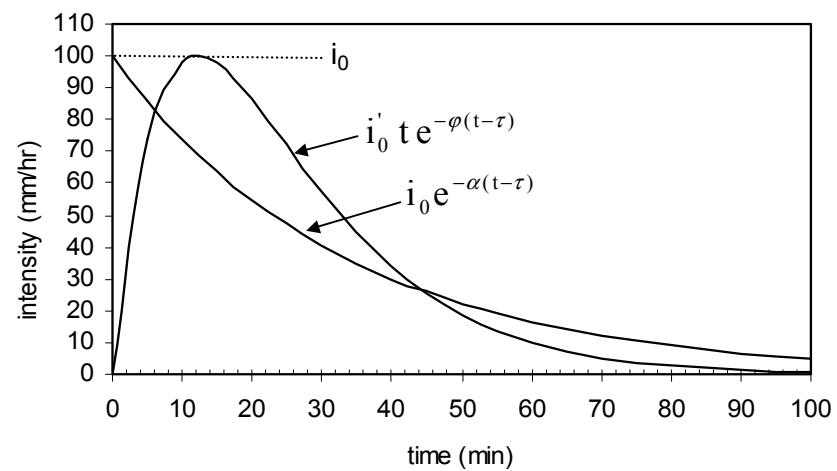

Fig. 1. Theoretical assumptions for the temporal shape of raincell intensities.

tial co-ordinates $z$, at time $t$ from the start of the storm. However, what is really a measurable variable is the cumulative rainfall denoted by $h(T, z)$, which represents the cumulative depth of rainfall in an interval with length $T$ at the point of co-ordinates $z$. It is therefore defined as:

$h(T, z)=\int_{0}^{T} \xi(t, z) d t$

The fundamental item in the model construction is, like in the RE model, the storm rain cell, which is characterized by a set of random and deterministic properties: Cell location in space, time of birth, cell center intensity and the decay rate in space are random variables, whereas the decay rate in time is assumed to be deterministic. The rainfall produced by a rain cell in an arbitrary point of coordinates $z$ can be obtained as follows: If $t$ is the elapsed time from the beginning of the storm, the rainfall intensity due to a cell born at a point $\boldsymbol{u}$ and time $\tau<t$ is given by:

$g(t-\tau,\|\boldsymbol{u}-\boldsymbol{z}\|)=g_{1}(t-\tau) \cdot g_{2}(\|\boldsymbol{u}-\boldsymbol{z}\|)$,

where

$g_{2}(\|\boldsymbol{u}-\boldsymbol{z}\|)=\exp \left(-\frac{\|\boldsymbol{u}-\boldsymbol{z}\|^{2}}{2 D^{2}}\right)$

$g_{2}$ being exactly as assumed in the original work by Rodriguez-Iturbe et al. (1987). For the description of the cell time evolution $\left(g_{1}(t-\tau)\right)$, two analytical approaches are considered:

(a) Exponential decay : $g_{1}(t-\tau)=i_{0} e^{-\alpha(t-\tau)}$

(b) Gamma - type decay : $g_{1}(t-\tau)=i_{0}^{\prime} t e^{-\varphi(t-\tau)}$.

Figure 1 shows the shapes of the corresponding functions. For a convenient further evaluation and comparison of the derived models, two additional conditions are imposed on the cited functions: (1) the area under the curves is the same, (2) the intensity at the maximum $\left(t=\varphi^{-1}\right)$ for the gamma-type function is equal to the intensity at $t=0$ for the exponential function. As a consequence, the following relations are derived for the variables introduced:

$i_{0}^{\prime}=i_{0} \varphi e$

$\varphi=\alpha e$.

The maximum rain-cell intensity, $i_{o}$, is assumed to be an independent, exponentially distributed random variable with mean $E\left[i_{o}\right]$ within the storm. As in the RE model (for a non-clustered process), the spatial distribution of cells is governed by a homogeneous two-dimensional Poisson process with spatial density $\lambda\left(L^{-2}\right)$. The time of birth of each cell $t_{b}$ relative to the storm onset is assumed to be an Erlang distribution with parameters $n$ and $\beta$. When $n=0$ the Erlang distribution becomes an exponential distribution. Assuming that features controlling rain cells occurrence in time and space are independent, the probability density function of the combined space-time process is:

$f_{t_{b}, y}(\tau, \boldsymbol{u})=\frac{\lambda \beta^{n+1} \tau^{n} e^{-\beta t}}{n !} ; \beta>0$ and $\tau>0$.

The rainfall intensity process at time $t$ for an arbitrary point of co-ordinates $z$, results from the addition of the contributions of all active cells at that moment, and can be analytically obtained as follows:

$\xi(1, \boldsymbol{z})=\int_{R^{2}} \int_{0}^{t} g_{1}(t-\tau) g_{2}(\|\boldsymbol{u}-\boldsymbol{z}\|) f_{t_{b}, y}(\tau, \boldsymbol{u}) d \tau d \boldsymbol{u}$

The integral over space covers the whole $R^{2}$ plane in which the Poisson process take place, under the assumption that the area covered by the storm is much larger than the area covered by a cell. The expressions of the moments for both the rainfall intensity process and the cumulative depth process are derived, for the two cases considered: exponentially shaped and gamma shaped cells.

\subsection{Model with exponential rain cells}

The mean of the rainfall intensity process is obtained from Eq. (10):

$E[\xi(t, \boldsymbol{z})]=\int_{R^{2}} \int_{0}^{t} E\left[g_{1}(t-\tau) g_{2}(\|\boldsymbol{u}-\boldsymbol{z}\|)\right] f_{t_{b}, y}(\tau, \boldsymbol{u}) d \tau d \boldsymbol{u}$

or

$E[\xi(t, z)]=\frac{2 \pi E\left[D^{2}\right] E\left[i_{0}\right] \lambda \beta^{n+1}}{n ! a}$

$\left[\left(t^{n}+\sum_{j=1}^{n} \frac{(-1)^{j} \prod_{i=0}^{j-1}(n-i)}{a^{j}} t^{n-j}\right) e^{-\beta t}-\frac{(-1)^{n} \cdot n !}{a^{n}} e^{-\alpha t}\right]$,

where $a=\alpha-\beta$. The covariance function of the rainfall intensity field in space and time is:

$\operatorname{Cov}\left[\xi\left(t_{1}, z_{1}\right), \xi\left(t_{2}, z_{2}\right)\right]=E\left[\xi\left(t_{1}, z_{1}\right) \cdot \xi\left(t_{2}, z_{2}\right)\right]$
$-E\left[\xi\left(t_{1}, z_{1}\right)\right] E\left[\xi\left(t_{2}, z_{2}\right)\right]$ 
After some analytical work (Rodriguez-Iturbe et al., 1987), Appendix A, we can express Eq. (12) as:

$\operatorname{Cov}\left[\xi\left(t_{1}, z_{1}\right), \xi\left(t_{2}, z_{2}\right)\right]$

$=\frac{\pi E\left[D^{2} e^{-\frac{d^{2}}{4 D^{2}}}\right] E\left[i_{0}^{2}\right] \lambda \beta^{n+1}}{n !} \int_{0}^{t_{2}} \tau^{n} e^{-\alpha\left(t_{1}-\tau\right)} e^{-\alpha\left(t_{2}-\tau\right)} e^{-\beta \tau} d \tau$

$=A_{2} e^{-\alpha\left(t_{1}+t_{2}\right)} \int_{0}^{t_{2}} \tau^{n} e^{b \tau} d \tau=\frac{\pi E\left[D^{2} e^{-\frac{d^{2}}{4 D^{2}}}\right] E\left[i_{0}^{2}\right] \lambda \beta^{n+1}}{b n !} e^{-\alpha t_{1}}$

$\left[\left(t_{2}^{n}+\sum_{j=1}^{n} \frac{(-1)^{j} \prod_{i=0}^{j-1}(n-i)}{b^{j}} t_{2}^{n-j}\right) e^{\alpha t_{2}}-\frac{(-1)^{n} n !}{b^{n}} e^{-\alpha t_{2}}\right]$

where

$A_{2}=\frac{\pi \cdot E\left[D^{2} \cdot \exp \left(-\frac{d^{2}}{4 D^{2}}\right)\right] \cdot E\left[i_{0}^{2}\right] \cdot \lambda \cdot \beta^{n+1}}{n !}$,

$b=2 \alpha-\beta, t_{1} \geq t_{2}$, and $d$ is the distance between the points $z_{1}$ and $z_{2}$. The autocovariance of $\xi(t, z)$ is obtained by letting $d=0$ in Eq. (13):

$\operatorname{Cov}\left[\xi\left(t_{1}, \boldsymbol{z}\right), \xi\left(t_{2}, \boldsymbol{z}\right)\right]=\frac{\pi E\left[D^{2}\right] E\left[i_{0}^{2}\right] \lambda \beta^{n+1}}{n ! b} e^{-\alpha t_{1}}$

$\left[\left(t_{2}^{n}+\sum_{j=1}^{n} \frac{(-1)^{j} \prod_{i=0}^{j-1}(n-i)}{b^{j}} t_{2}^{n-j}\right) e^{\alpha t_{2}}-\frac{(-1)^{n} n !}{b^{n}} e^{-\alpha t_{2}}\right]$

The variance function of $\xi(t, z)$ is (from Eq. (14) with $t_{1}=$ $\left.t_{2}=t\right)$ :

$$
\begin{aligned}
& \operatorname{Var}[\xi(t, z)]=\frac{\pi E\left[D^{2}\right] E\left[i_{0}^{2}\right] \lambda \beta^{n+1}}{n ! b} \\
& {\left[\left(t^{n}+\sum_{j=1}^{n} \frac{(-1)^{j} \prod_{i=0}^{j-1}(n-i)}{b^{j}} t^{n-j}\right) e^{-\beta t}-\frac{(-1)^{n} n !}{b^{n}} e^{-2 \alpha t}\right]}
\end{aligned}
$$

The mean cumulative depth of rainfall is:

$$
\begin{aligned}
& E[h(T, z)]=\int_{0}^{T} E[\xi(t, z)] d t \quad \text { or } \\
& E[h(T, z)]=\frac{2 \pi E\left[D^{2}\right] E\left[i_{0}\right] \lambda \beta^{n}}{a}\left\{\frac{a}{\alpha \beta^{n}}+\frac{(-1)^{n} \beta}{\alpha a^{n}} e^{-\alpha T}\right. \\
& \left.-\frac{1}{n !}\left[T^{n}+\sum_{j=1}^{n} \frac{\prod_{i=0}^{j-1}(n-i)}{\beta^{j} a^{j}} \cdot\left(\sum_{q=0}^{j}(-1)^{q} \beta^{q} a^{j-q}\right) T^{n-j}\right] e^{-\beta T}\right\}(16)
\end{aligned}
$$

where $a=\alpha-\beta$. The total cumulative depth can be regarded as the limiting value when $T \rightarrow \infty$. The resulting expression is:

$\lim _{T \rightarrow \infty} E[h(t, z)]=E[h(\infty, z)]=\frac{2 \pi E\left[D^{2}\right] E\left[i_{0}\right] \lambda}{\alpha}$

The ratio between both values from Eqs. (16) and (17) provides the normalized mean function of the process:

$$
\begin{aligned}
& \mu(T, \alpha, \beta, n)=\frac{E[h(T, z)]}{E[h(\infty, z)]}=1+\frac{(-1)^{n} \beta^{n+1}}{a^{n+1}} e^{-\alpha T}-\frac{\alpha \beta^{n}}{a n !} \\
& {\left[T^{n}+\sum_{j=1}^{n} \frac{\prod_{i=0}^{j-1}(n-i)}{\beta^{1} a^{j}}\left(\sum_{q=0}^{j}(-1)^{q} \beta^{q} a^{j-q}\right) T^{n-j}\right] e^{-\beta T}}
\end{aligned}
$$

The covariance function of the cumulative rainfall process $h(T, z)$ is:

$\operatorname{Cov}\left[h\left(T_{1}, z_{1}\right) h\left(T_{2}, z_{2}\right)\right]=\int_{0}^{T_{1}} \int_{0}^{T_{2}} \operatorname{Cov}\left[\xi\left(t_{1}, z_{1}\right) \xi\left(t_{2}, z_{2}\right)\right] d t_{1} d t_{2}$

$=\frac{\lambda \beta^{n+1} \pi E\left[D^{2} e^{-\frac{d^{2}}{4 D^{2}}}\right] E\left[i_{0}^{2}\right]}{n ! \alpha a b}\left\{\frac{(-1)^{n} n ! b}{\alpha a^{n}} e^{-\alpha T_{1}}\right.$

$+\frac{(-1)^{n} n ! a}{\alpha b^{n}}\left(1-e^{-\alpha T_{1}}\right) e^{-\alpha T_{2}}-\frac{b}{\beta}$

$\left[T_{1}^{n}+\sum_{j=1}^{n} \prod_{i=0}^{j-1}(n-i)\left(\sum_{q=0}^{j} \frac{(-1)^{q}}{\beta^{i-q} a^{q}}\right) T_{1}^{n-j}\right] e^{-\beta T_{1}}$

$-\left[\left(T_{1}^{n}+\sum_{j=1}^{n}(-1)^{j} \prod_{i=0}^{j-1}(n-i)\left(\sum_{q=0}^{j} \frac{1}{a^{j-q} b^{q}}\right) T_{1}^{n-j}\right)\right.$

$\left.\left.e^{a T_{1}}-(-1)^{n} n ! \sum_{j=0}^{n} \frac{1}{b^{j} a^{n-j}}\right] e^{-\alpha T_{2}}+\frac{n ! a b}{\alpha \beta^{n+1}}\right\}$

where $\left\{\begin{array}{l}a=\alpha-\beta \\ b=2 \alpha-\beta\end{array}\right\} \quad$ and $\quad T_{2} \geq T_{1}$.

The variance of $h(T, z)$ (by setting $z_{1}=z_{2}=z(d=0)$ and $T_{1}=T_{2}=T$ in Eq. 19) is:

$\operatorname{Var}=[h(T, z)]=\frac{\lambda \beta^{n+1} \pi E\left[D^{2}\right] E\left[i_{0}^{2}\right]}{\alpha^{2} a b}$

$\left\{(-1)^{n}\left(\frac{b}{a^{n}}+\frac{a}{b^{n}}+\alpha \sum_{j=0}^{n}\left(\frac{1}{b^{j} a^{n-j}}\right)\right) e^{-\alpha T}\right.$

$-(-1)^{n} \frac{a}{b^{n}} e^{-2 \alpha T}-\frac{\alpha}{n !}\left[\frac{2 a}{\beta} T^{n}+\sum_{j=1}^{n}\left[\prod_{i=0}^{j-1}(n-i)\right.\right.$

$\left.\left.\left.\sum_{q=0}^{j}\left(\frac{b}{\beta} \frac{(-1)^{q}}{\beta^{j-q} a^{q}}+\frac{(-1)^{j}}{a^{j-q} b^{q}}\right)\right] T^{n-j}\right] e^{-\beta T}+\frac{a b}{\beta^{n+1}}\right\}$ 
$\lim _{T \rightarrow \infty} \operatorname{Cov}\left[h\left(T_{1}, z_{1}\right), h\left(T_{2}, z_{2}\right)\right]=$

$\operatorname{Cov}\left[h\left(\infty, z_{1}\right), h\left(\infty, z_{2}\right)\right]=\frac{\lambda \pi e\left[D^{2} e^{\frac{d^{2}}{4 D^{2}}}\right] E\left[i_{0}^{2}\right]}{\alpha^{2}}$

From Eqs. (21) and (22) the correlation function of total depth field $(T \rightarrow \infty)$ is described by the quadratic exponential function:

$\rho_{h(\infty, z)}=\frac{\operatorname{Cov}\left[h\left(\infty, z_{1}\right), h\left(\infty, z_{2}\right)\right]}{\operatorname{Var}[h(\infty, z)]}=\frac{E\left[D^{2} e^{\frac{d^{2}}{4 D^{2}}}\right]}{E\left[D^{2}\right]}$

\subsection{Model with gamma-type rain cells}

Similar analytical derivations have been undertaken for the model based on gamma-type cells. The corresponding expressions for the relevant first and second order moments are presented. The mean of the rainfall intensity process can be again obtained from Eq. (10), but introducing now in the analysis the new $g_{1}$ gamma-type function: $g_{1}(t-\tau)=$ $i_{0}^{\prime} t e^{-\varphi(t-\tau)}$

$E[\xi(t, z)]$

$=\int_{R^{2}} \int_{0}^{t} E\left[i_{0}\right] \varphi \cdot e(t-\tau)^{-\varphi(t-\tau)} E\left[e^{\frac{-r^{2}}{2 D^{2}}}\right] \frac{\lambda \beta^{n+1} \tau^{n} e^{-\beta \tau}}{n !} d \tau r d r d \theta$

$=\frac{2 \pi \varphi e E\left[D^{2}\right] E\left[i_{0}\right] \lambda \beta^{n+1}}{n ! k^{2}}$

$\left\{\left(t^{n}+\sum_{j=1}^{n} \frac{(-1)^{j}(j+1) \prod_{i=0}^{j-1}(n-i)}{k^{j}} t^{n-j}\right) e^{-\beta t}\right.$

$\left.-\frac{(-1)^{n} n !}{k^{n}}(k t+n+1) e^{-\varphi t}\right\}$

where $k=\varphi-\beta$.

With a similar analytical treatment, the covariance function of the rainfall intensity field in space and time is obtained as follows:

$\operatorname{Cov}\left[\xi\left(t_{1}, z_{1}\right) \xi\left(t_{2}, z_{2}\right)\right]=\frac{\pi[\varphi e]^{2} E\left[D^{2} e^{-\frac{d^{2}}{4 D^{2}}}\right] E\left[i_{0}^{2}\right] \lambda \beta^{n+1}}{n !}$

$\int_{0}^{t_{2}} \tau^{n}\left(t_{1}-\tau\right)\left(t_{2}-\tau\right) e^{-\varphi\left(t_{1}-t_{2}\right)} e^{(2 \varphi-\beta) \tau} d \tau$

$=\frac{A e^{-\varphi t_{1}}}{h^{2}}\left\{\left[\left(t_{1}-t_{2}\right) t_{n}^{2}+\sum_{j=1}^{n}\left[\frac{(-1)^{j} \cdot(j+1)}{h^{j}}\right.\right.\right.$

$\left.\left.\left(t_{1} \prod_{i=0}^{j-1}(n-i)-t_{2} \prod_{i=0}^{j-1}(n+1-i)\right)\right] t_{2}^{n-j}+\frac{(-1)^{n}(n+2) !}{h^{n+1}}\right]$

$\left.e^{k t_{2}}-\frac{(-1)^{n} n !}{h^{n}}\left[h\left(t_{2}+\frac{n+1}{h}\right) t_{1}+(n+1)\left(t_{2}+\frac{n+2}{h}\right)\right] e^{-\varphi t_{2}}\right\}$ where

$A=\frac{\pi[\phi e]^{2} E\left[D^{2} e^{-\frac{d^{2}}{4 D^{2}}}\right] E\left[i_{0}^{2}\right] \lambda \beta^{n+1}}{n !}, h=2 \phi-\beta$ and $t_{1} \geq t_{2}$.

The variance of the rainfall intensity process results from Eq. (25), with $z_{1}=z_{2}=z(d=0)$ and $t_{1}=t_{2}=t$.

$\operatorname{Var}[\xi(t, z)]=\frac{\pi[\varphi e]^{2} E\left[D^{2}\right] E\left[i_{0}^{2}\right] \lambda \beta^{n+1}}{n ! h^{3}}$

$\left\{\left[2 t^{n}+\sum_{j=1}^{n} \frac{(-1)^{j}(j+1)(j+2) \prod_{i=0}^{j-1}(n-i)}{h^{j}} t^{n-j}\right]-e^{-\beta t}\right.$

$\left.-\frac{(-1)^{n} n !}{h^{n}}\left[t^{2}+\frac{2(n+1)}{h} t+(n+1)(n+2)\right] e^{-2 \varphi t}\right\}$.

The mean cumulative depth of rainfall at different time intervals is:

$E[h(T, z)]=\int_{0}^{T} E[\xi(t, z)] d t=\frac{2 \pi e E\left[D^{2}\right] E\left[i_{0}\right] \lambda \beta^{n}}{k}$

$\left\{\frac{k}{\varphi \beta^{n}}+\frac{(-1)^{n} \beta}{k^{n}}\left[T+\frac{1}{\varphi}+\frac{(n+1)}{k}\right] e^{-\varphi T}\right.$

$-\frac{\varphi}{k n !}\left[T^{n}+\sum_{j=1}^{n} \frac{\prod_{i=0}^{j-1}(n-i)}{\beta^{j} k^{j}}\left(\sum_{q=0}^{j}(-1)^{q}(k+1) \beta^{q} k^{j-q}\right)\right.$

$\left.\left.T^{n-j}\right] e^{-\beta T}\right\}$.

The value of the mean cumulative depth at the end of the storm can be derived through computation of the limiting form of Eq. (27) when $T \rightarrow \infty$ :

$\lim _{t \rightarrow \infty} E[h(T, z)]=E[h(\infty, z)]=$

$\frac{2 \pi e E\left[D^{2}\right] E\left[i_{0}\right] \lambda}{\varphi}=\frac{2 \pi E\left[D^{2}\right] E\left[i_{0}\right] \lambda}{\alpha}$

It is important to remark that Eq. (28) is independent of the temporal shape of the rain cell, as should be expected. In fact, the total contribution of cells during the whole process depends on the number of cells that occurred and the volume of rainfall associated to them, rather than the internal features describing the space-time evolution of every single cell that occurred during the event. The ratio between Eq. (27) and Eq. (28) gives the normalized mean function:

$$
\begin{aligned}
& \mu(T, \varphi, \beta, n)=\frac{E[h(t, z)]}{E[h(\infty, z)]} \\
& =1+\frac{(-1)^{n} \beta^{n+1} \varphi}{k^{n+1}}\left[T+\frac{1}{\varphi}+\frac{n+1}{k}\right] e^{-\varphi T}-\frac{\varphi^{2} \beta^{n}}{k^{2} n !} \\
& {\left[T^{n}+\sum_{j=1}^{n} \frac{\prod_{i=0}^{j-1}(n-i)}{\beta^{j} k^{j}}\left(\sum_{q=0}^{j}(-1)^{q}(q+1) \beta^{q} k^{j-q}\right) T^{n-j}\right] e^{-\beta T}}
\end{aligned}
$$


The covariance of the cumulative depth process results in a relatively more complicated expression as compared to the previous model. But again, the outcome of the analytical development is an explicit expression that can be conveniently handled and computed, and therefore verifies the basic requirement of the model for further calibration and parameter estimation.

$$
\begin{aligned}
& \operatorname{Cov}\left[h\left(T_{1}, z_{1}\right) h\left(T_{2}, z_{2}\right)\right]=\int_{0}^{T_{1}} \int_{0}^{T_{2}} \operatorname{Cov}\left[\xi\left(t_{1}, z_{1}\right) \xi\left(T_{2}, z_{2}\right)\right] d t_{1} d t_{2} \\
& =\frac{\pi[\varphi e]^{2} E\left[D^{2} e^{-\frac{d^{2}}{4 D^{2}}}\right] E\left[i_{0}^{2}\right] \lambda \beta^{n+1}}{n ! \varphi h^{2} k}\left\{\frac{(-1)^{n} n ! h^{2}}{\varphi^{2} k^{n}}\right. \\
& \left(T_{1}+\frac{1}{\varphi}+\frac{n+1}{k}\right) e^{-\varphi T_{1}}-\frac{(-1)^{n} n ! k}{\varphi h^{n}} \\
& {\left[(n+1)\left(T_{2}+\frac{1}{\varphi}+\frac{n+2}{h}\right)\left(1-e^{-\varphi T_{1}}\right)-h\left(T_{1}+\frac{1}{\varphi}\right)\right.} \\
& \left.\left(T_{2}+\frac{1}{\varphi}+\frac{n+1}{h}\right) e^{-\varphi T_{1}}\right] e^{-\varphi T_{2}}-\frac{h^{2}}{\beta \varphi k} \\
& {\left[T_{1}^{n}+\sum_{j=1}^{n} \prod_{i=0}^{j-1}(n-i)\left(\sum_{q=0}^{j} \frac{(-1)^{q}(q+1)}{k^{q} \beta^{j-q}}\right) T_{1}^{n-j}\right] e^{-\beta T_{1}}} \\
& -\left\{\left[\left(T_{2}+\frac{1}{\varphi}-T_{1}\right) T_{1}^{n}+\sum_{j=1}^{n}\left[(-1)^{j}\left(\sum_{q=0}^{j} \frac{(q+1)}{h^{q} k^{j-q}}\right)\right.\right.\right. \\
& \left.\left(\left(T_{2}+\frac{1}{\varphi}\right) \prod_{i=0}^{j-1}(n-i)-T_{1} \prod_{i=0}^{j-1}(n+1-i)\right)\right] T_{1}^{n-j} \\
& \left.+\frac{(-1)^{n}(n+1) !}{k} \sum_{j=0}^{n+1} \frac{(j+1)}{h^{j} k^{n-j}}\right] e^{k T_{1}}-(-1)^{n} n ! \\
& {\left[\left(T_{2}+\frac{1}{\varphi}+\frac{n+1}{k}\right) \sum_{j=o}^{n}\left(\frac{j+1}{h^{j} k^{n-j}}\right)\right.} \\
& \left.\left.\left.+\frac{(n+1)(n+2)}{h^{n+1}}\right]\right\} e^{\varphi T_{2}}+\frac{n ! h^{2} k}{\varphi^{3} \beta^{n+1}}\right\}
\end{aligned}
$$

where $\left\{\begin{array}{l}a=\varphi-\beta \\ b=2 \varphi-\beta\end{array}\right\} \quad$ and $\quad T_{2} \geq T_{1}$.

Again, the variance of the cumulative depth process can be obtained by setting $z_{1}=z_{2}=z(d=0)$ and $T_{1}=T_{2}=T$ in Eq. (30).

The expressions of the variance and the covariance at the end of the storm (total cumulative depth process) are given by:

$$
\begin{aligned}
& \lim _{T \rightarrow \infty} \operatorname{Var}[h(T, z)]=\operatorname{Var}[h(\infty, z)]=\frac{\lambda \pi e^{2}\left[D^{2}\right] E\left[i_{0}^{2}\right]}{\varphi^{2}} \\
& \lim _{T \rightarrow \infty} \operatorname{Cov}\left[h\left(T_{1}, z_{1}\right), h\left(T_{2}, z_{2}\right)\right] \\
& =\operatorname{Cov}\left[h\left(\infty, z_{1}\right), h\left(\infty, z_{2}\right)\right]=\frac{\lambda \pi e^{2} E\left[D^{2} e^{-\frac{d^{2}}{4 D^{2}}}\right] E\left[i_{0}^{2}\right]}{\varphi^{2}}
\end{aligned}
$$

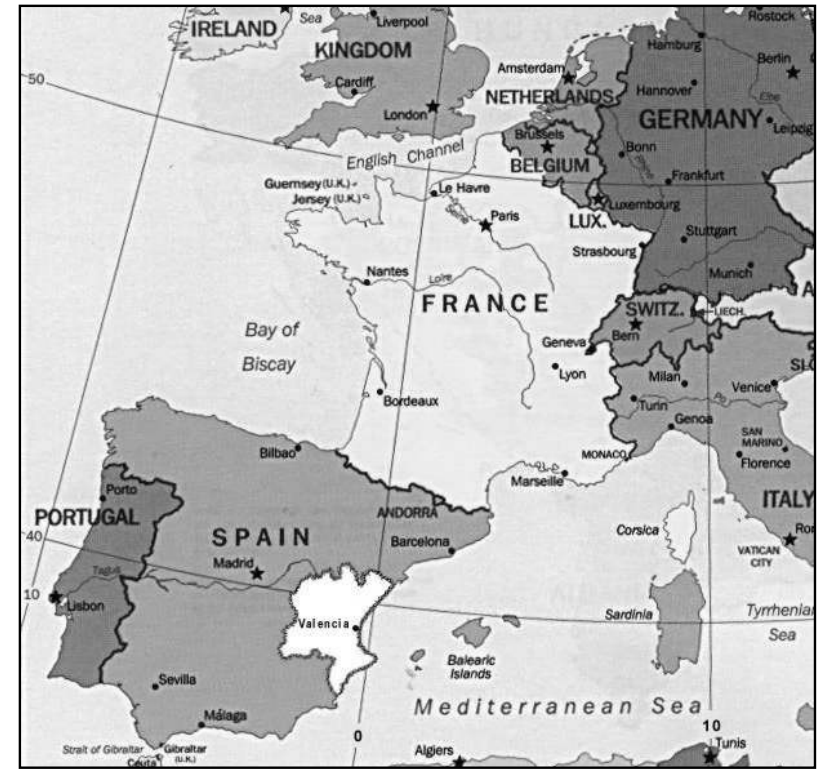

Fig. 2. Location of the region managed by the Jucar River Water Authority (Spain).

The correlation function of the total depth $(t \rightarrow \infty)$ is identical to Eq. (23). This is explained by the fact that there are no differences concerning spatial features defining rain cells between the two postulated models.

\section{Data description}

From 1961 until 1990 there were 176 rainfall events where precipitation reached $100 \mathrm{~mm} \mathrm{~d}^{-1}$ in at least one point of the Jucar River basin (Fig. 2).

These kinds of rainfall events are mostly associated with dynamic instability at high levels in the troposphere. At the sea level, low pressures appear over the Southeast of the Mediterranean Sea. This configuration, added to an anticyclone over central Europe, forces eastern winds towards the Mediterranean Spanish coast. This synoptic framework along with mesoscale and orographic factors and sea temperature complete the proper conditions to produce heavy rainfall events in this region. The available data have been provided by Confederación Hidrográfica del Júcar, the Regional Water Authority, which is operating an automatic pluviograph network consisting of a total of 106 raingauges giving on-line information (intensities in $\mathrm{mm} \mathrm{h}^{-1}$ ) with a time level of aggregation of $5 \mathrm{~min}$.

The data used to calibrate the described models consists of 30 rain events that occurred during 1991 to 2000. Every period contains the rainfall data of all raingauges (even those with no rainfall), for a number of consecutive rainy days in the area.

The following tasks have been performed for each of the data series: 
(a) Eliminate stations containing a non-negligible percentage of errors or missing values.

(b) For the rest of the stations, verify and complete the series, using simple time interpolation techniques.

(c) Graphical representation of spatial distribution of cumulative rainfall for each period.

(d) Graphical representation in time of $\sum \xi_{i}(t)$, where $\xi_{i}$ is the rainfall intensity of raingauge " $i$ ".

(e) From (d) and (e), selection of independent rainfall events and main spatial areas affected in each case.

(f) Once the event has been defined in space and time, the data corresponding to each one is reduced to a set of rainfall intensity series including only the selected raingauges in each case, and with a common start and finish time.

(g) Among all the independent events, selection of the most intense ones, according to both cumulative rainfall values and maximum rainfall intensities

Table 1 summarizes some information about the selected events. There are events in all months of the year except for March. The majority of these events were recorded in September, October and November, corresponding to the period of the year with a higher frequency of intense convective storms over the region. The duration of the events ranges from $9 \mathrm{~h}$ to $107 \mathrm{~h}$. The column entitled "Pluv. Nr" in Table 1 indicates the number of raingauges with representative data for each of the events considered. The table also shows the computed mean $(\mathrm{mm})$, variance $\left(\mathrm{mm}^{2}\right)$ and coefficient of variation for the total cumulative depth of each event.

\section{Parameter estimation}

The seven parameters of the model are estimated for each of the 30 events under consideration. The estimation process is undertaken by the method of moments, by equating the analytic expressions of the statistical moments to the observed ones in the sample. The parameters to be estimated are:

- $\lambda$ : controls birth of raincells, according to a Poisson process.

- $D$ : is associated with the spatial attenuation of the cell intensity. It is assumed that $D^{-2}$ follows a gamma distribution with parameters $\delta$ and $\theta$.

- $1_{0}$ : represents the initial cell center intensity, and is exponentially distributed with mean $E\left[i_{0}\right]$.

- $\alpha$ : parameter defining the exponential time-evolution of raincell intensity. When the time evolution is described by a gamma-type function, the parameter to estimate is $\varphi$, with the following relationship between them: $\varphi=$ $\alpha \cdot e$.
- Parameters $\beta$ and $n$ : Control the time of birth of each cell, relative to the storm outset, following an Erlang distribution.

The estimation process comprises two stages. First, the parameters affecting the spatial properties of the rainfall intensity field are estimated. Then, the parameters controlling the temporal structure and evolution of the rainfall intensity during the course of the event are estimated.

\subsection{Spatial parameters}

\subsubsection{Estimation of $\delta$ and $\theta$ parameters}

The cell density $\lambda$ and the parameters $\delta$ and $\theta$, which control the attenuation of precipitation in space, may be expressed as functions of the moments of total depth (Jacobs et al., 1988). With regard to $\delta$ and $\theta$ parameters, they are estimated by fitting Eq. (23) to the empirical function for a given storm.

Assuming that $D^{-2}$ follows a gamma distribution (Rodriguez-Iturbe et al., 1987), the correlation function is given by:

$\rho_{h(\infty, z)}(d)=\left(\frac{d^{2}}{4 \theta}+1\right)^{1-\delta}$

In order to estimate $\delta$ and $\theta$ it is necessary to have an estimator of the covariance. The most commonly quoted estimator of the covariance of a one-dimensional random process is:

$\operatorname{Co} v(\tau)=\frac{1}{(T-\tau)} \int_{0}^{T-\tau}(x(t)-\overline{x(t)})(x(t+\tau)-\overline{x(t)}) d t$

The expected value of this estimator is less than the value of the population moment. To overcome this fact Jacobs et al. (1988) apply an unbiased estimator of the correlation function:

$c \hat{o} r_{x}\left[h\left(t, z_{1}\right) h\left(t, z_{2}\right)\right]$

$=\operatorname{co} r\left[h\left(t, z_{1}\right) h\left(t, z_{2}\right)\right]\left(1-\gamma\left(L_{1}, L_{2}\right)\right)+\gamma\left(L_{1}, L_{2}\right)$

where $\gamma\left(L_{1}, L_{2}\right)$ is the variance function (Vanmarcke, 1983). This function, for the RE model, is approximated by Rodriguez-Iturbe et al. (1987) as:

$\gamma\left(L_{1}, L_{2}\right)=\left(1+\frac{L_{1}^{2}}{4 \pi D^{2}}\right)^{-\frac{1}{2}}\left(1+\frac{L_{2}^{2}}{4 \pi D^{2}}\right)^{-\frac{1}{2}}$

Regarding the variance, Jacobs et al. (1988) give an unbiased estimate:

$V \hat{a} r_{c}[h(t, z)]=\operatorname{Var}[h(t, z)]\left(\frac{1}{1-\gamma\left(L_{1}, L_{2}\right)}\right)$.

The correlation function is then corrected through an iterative routine. A value of $\delta$ and $\theta$ is estimated by search of the value which minimizes the mean square error of the corrected correlation function when compared to the theoretical 
Table 1. Historical data for the selected rainfall events

\begin{tabular}{|c|c|c|c|c|c|c|c|c|c|}
\hline \multirow[b]{2}{*}{1 January 1991} & \multicolumn{2}{|c|}{ Start } & \multicolumn{2}{|c|}{ End } & \multirow{2}{*}{$\begin{array}{l}\text { Hours } \\
43.33\end{array}$} & \multirow{2}{*}{$\begin{array}{l}\text { Pluv. Nr. } \\
31\end{array}$} & \multirow{2}{*}{$\begin{array}{l}\text { Mean }(\mathrm{mm}) \\
37.9\end{array}$} & \multirow{2}{*}{$\begin{array}{l}\text { Variance }\left(\mathrm{mm}^{2}\right) \\
710.2\end{array}$} & \multirow{2}{*}{$\begin{array}{l}\text { C.V. } \\
0.7\end{array}$} \\
\hline & $22 / 01 / 91$ & $17: 40$ & 24/01/91 & $13: 00$ & & & & & \\
\hline 2 January 1991 & 24/01/91 & $13: 00$ & 27/01/91 & $21: 00$ & 80.00 & 50 & 49.3 & 1972.4 & 0.9 \\
\hline 1 February 1993 & $31 / 01 / 93$ & $14: 25$ & $03 / 02 / 93$ & $06: 05$ & 63.67 & 52 & 73.5 & 3269.5 & 0.8 \\
\hline 2 February 1993 & $03 / 02 / 93$ & $05: 55$ & $05 / 02 / 93$ & $03: 15$ & 45.33 & 63 & 26.5 & 319.3 & 0.7 \\
\hline 1 April 1991 & $14 / 04 / 91$ & $16: 10$ & $15 / 04 / 91$ & $20: 20$ & 28.17 & 62 & 19.5 & 196.6 & 0.7 \\
\hline 2 April 1991 & $16 / 04 / 91$ & $13: 10$ & $17 / 04 / 91$ & $22: 40$ & 33.50 & 39 & 28.5 & 342.0 & 0. \\
\hline May 1992 & $02 / 05 / 92$ & $18: 55$ & $04 / 05 / 92$ & $13: 15$ & 42.33 & 49 & 68.7 & 6375.5 & 1.2 \\
\hline 1 June 1992 & $13 / 06 / 92$ & $12: 25$ & $14 / 06 / 92$ & $09: 45$ & 21.33 & 59 & 22.6 & 225.2 & 0.7 \\
\hline 2 June 1992 & $15 / 06 / 92$ & $14: 45$ & $16 / 06 / 92$ & $13: 25$ & 25.33 & 37 & 29.8 & 394.0 & 0.7 \\
\hline June 1993 & 08/06/93 & $16: 45$ & 09/06/93 & $02: 15$ & 9.33 & 28 & 9.9 & 121.4 & 1.1 \\
\hline July 1993 & 01/07/93 & $18: 05$ & 02/07/93 & $05: 55$ & 11.83 & 32 & 18.8 & 642.4 & 1.3 \\
\hline August 1996 & $14 / 08 / 96$ & $15: 05$ & $15 / 08 / 96$ & $03: 35$ & 12.50 & 29 & 13.3 & 177.6 & 1.0 \\
\hline September 1991 & 06/09/91 & 07:00 & 06/09/91 & $21: 20$ & 14.33 & 63 & 13.1 & 123.8 & 0.8 \\
\hline September 1992 & 26/09/92 & $14: 45$ & 27/09/92 & $07: 45$ & 16.00 & 36 & 14.0 & 108.3 & 0.7 \\
\hline 1 September 1994 & 27/09/94 & $13: 55$ & 28/09/94 & $11: 15$ & 21.33 & 38 & 13.8 & 136.5 & 0.8 \\
\hline 2 September 1994 & 28/09/94 & $11: 15$ & $30 / 09 / 94$ & 04:05 & 39.17 & 65 & 39.8 & 497.4 & 0.6 \\
\hline September 1996 & $10 / 09 / 96$ & 09:20 & $12 / 09 / 96$ & 19:00 & 57.67 & 78 & 75.5 & 7054.8 & 1.1 \\
\hline 1 September 1997 & 29/09/97 & $03: 10$ & 29/09/97 & $14: 45$ & 11.50 & 67 & 11.1 & 122.3 & 1.0 \\
\hline 2 September 1997 & 29/09/97 & $16: 25$ & $30 / 09 / 97$ & $05: 15$ & 12.83 & 21 & 25.2 & 1282.6 & 1.4 \\
\hline 3 September 1997 & $30 / 09 / 97$ & $07: 15$ & $01 / 10 / 97$ & $11: 05$ & 27.83 & 54 & 71.4 & 4379.3 & 0.9 \\
\hline October 1991 & 04/10/91 & 08:00 & 05/10/91 & $07: 20$ & 23.33 & 23 & 41.9 & 3250.0 & 1.4 \\
\hline October 1992 & 07/10/92 & $23: 00$ & 09/10/92 & $06: 20$ & 31.33 & 32 & 38.0 & 1809.6 & 1.1 \\
\hline October 1993 & $25 / 10 / 93$ & $23: 00$ & $28 / 10 / 93$ & $11: 50$ & 60.83 & 70 & 69.8 & 4056.4 & 0.9 \\
\hline 1 October 1994 & 05/10/94 & $12: 15$ & 06/10/94 & $07: 35$ & 19.33 & 27 & 19.2 & 308.3 & 0.9 \\
\hline 2 October 1994 & 09/10/94 & $04: 45$ & $10 / 10 / 94$ & $04: 45$ & 24.00 & 34 & 54.5 & 998.5 & 0.6 \\
\hline 3 October 1994 & $10 / 10 / 94$ & $13: 05$ & $12 / 10 / 94$ & $04: 25$ & 39.33 & 43 & 47.5 & 2491.8 & 1.1 \\
\hline November 1993 & $03 / 11 / 93$ & $22: 00$ & $04 / 11 / 93$ & $22: 30$ & 24.50 & 85 & 24.0 & 180.1 & 0. \\
\hline Dicember 1992 & $23 / 12 / 92$ & $07: 30$ & $27 / 12 / 92$ & $18: 00$ & 106.50 & 76 & 77.1 & 2690.2 & 0.7 \\
\hline Dicember 1997 & $17 / 12 / 97$ & $03: 55$ & $18 / 12 / 97$ & $15: 15$ & 35.33 & 49 & 19.4 & 369.1 & 1.0 \\
\hline October 2000 & $22 / 10 / 00$ & $03: 45$ & $25 / 10 / 00$ & $16: 45$ & 85.00 & 105 & 209.9 & 15765.6 & 0.6 \\
\hline
\end{tabular}

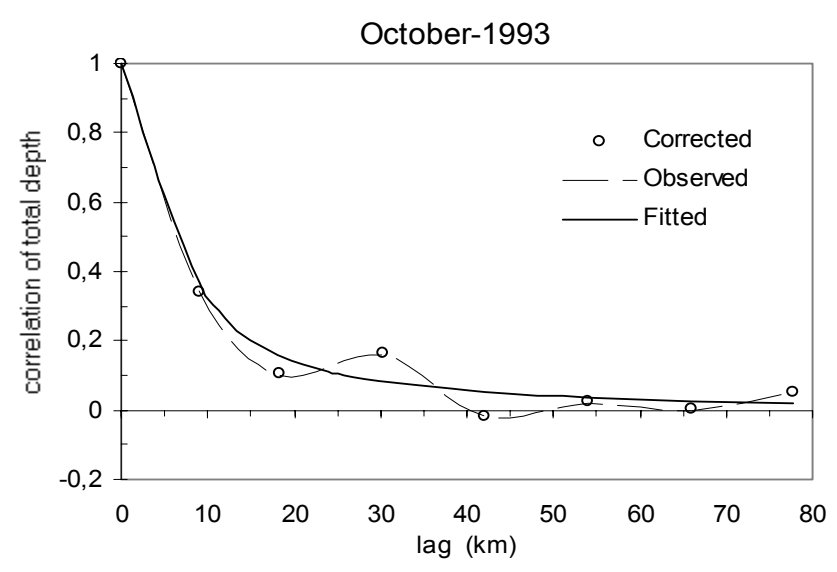

Fig. 3. Spatial correlation function for the October 1993 event.

total depth correlation function. Figure 3 shows the correlation function of total depth for one of the sample events, ocurred during the days 25 to 28 October 1993. Estimates of the correlation function have been obtained by lumping together gauge pairs of near equivalent separation in $\mathrm{km}$. The estimated values for $\delta$ and $\theta$ are $\delta=1.705$ and $\theta=6.435$ for the event of October 1993, referred to Fig. 3. The derived value for $E\left[D^{2}\right]$ in this case is $9.1 \mathrm{~km}^{2}$.

\subsubsection{Estimation of $\lambda$ parameter}

From Eqs. (17) and (21) or Eqs. (28) and (31), the cell density $\lambda$ for each storm event can be expressed as a function of the moments of total depth and the previously estimated value of $E\left[D^{2}\right]$ as:

$\lambda=\frac{1}{2 \pi E\left[D^{2}\right]} \frac{E^{2}[h(\infty, z)]}{V \hat{a} r_{c}[h(\infty, z)]}$

For the example under consideration (October-1993 event), the estimated value for this parameter is $\lambda=0.021$ cells $/ \mathrm{km}^{2}$.

\subsection{Temporal parameters}

There are three parameters governing the storm's theoretical temporal structure, according to the previous analytical development presented: $\alpha$-related to the cell's longevity, $\beta$ and $n$-related to the cell's temporal arrival distribution. 


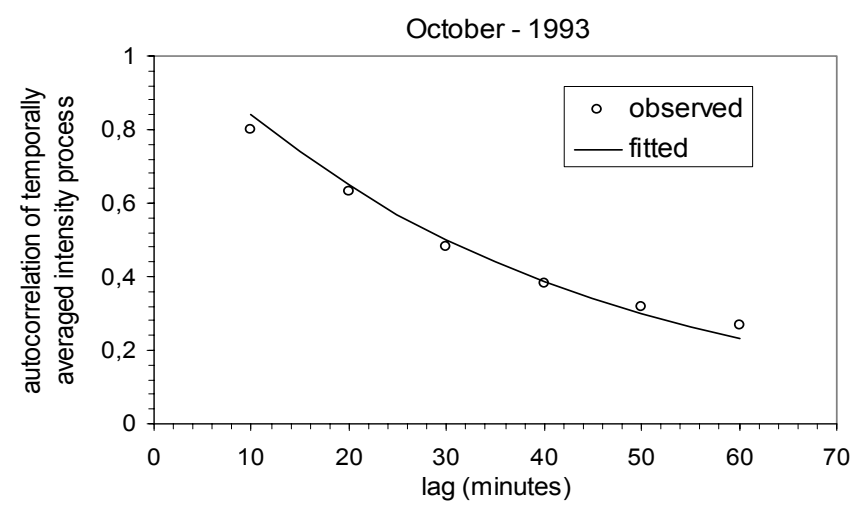

Fig. 4. Temporal autocorrelation function - October 1993 event.

\subsubsection{Estimation of $\alpha$ parameter}

In the work by Jacobs et al. (1988), $\alpha$ and $\beta$ are estimated by using the normalized mean and variance. Some difficulties are encountered when applying that method, as explained by the authors. By observing the expression of the normalized mean (Eqs. 18 or 29), it can be concluded that this function is not sensitive enough to provide a suitable procedure for a robust estimation of $\alpha$. In most cases it should be expected that $\alpha \gg \beta$, for which the normalized mean function approaches a limit which is independent of $\alpha$. This is consistent with the fact that both functions, the normalized mean and normalized variance of the process, provide a description of the evolution of the storm, and this evolution is mostly controlled by $\beta$ and $n$ (for our events the mean of the cell's birth time: $\left.(n+1) \beta^{-1} \in(200 \mathrm{~min}, 3000 \mathrm{~min})\right)$, whereas the $\alpha$ parameter governs the cell's internal evolution (for our events $\alpha^{-1} \in$ (12 min, $62 \mathrm{~min})$ ).

The difficulties reported by Jacobs et al. (1988) have been tackled incorporating in the parameter estimation procedure the correlation function of the temporally averaged intensity process $\xi^{(T)}(t, z)$, defined over intervals of length $T$. Jacobs et al. (1988) derived the expressions for mean, variance and covariance when $n=0$. If we consider the time at the end of the storm event (we may assume $t \rightarrow \infty$ in mathematical terms), then the following expression is obtained (model with exponential rain cells):

$\operatorname{Corr}\left[\xi^{(T)}\left(t, z_{1}\right), \xi^{(T)}\left(T+k T, z_{2}\right)\right]$

$=\frac{\beta e^{-\alpha k T}}{2} \frac{\left(e^{\alpha T}-1\right)\left(e^{-\beta T}-e^{-\alpha T}\right)}{(\alpha-\beta)+\beta e^{-\alpha T}-\alpha e^{-\beta T}}$

It should be remarked here that the above limit is independent of $n$. For small values of the $\beta T$ product, it is possible to approximate $\left[e^{-\beta T}\right]$ with $[1-\beta T]$, and therefore, the previous expression can be rewritten as:

$\operatorname{Corr}\left[\xi^{(T)}\left(t, z_{1}\right), \xi^{(T)}\left(T+k T, z_{2}\right)\right]$

$=\frac{e^{-\alpha(k-1) T}}{2} \frac{\left(1-e^{-\alpha T}\right)^{2}}{\alpha T-1+e^{-\alpha T}}$

which is independent of $\beta$.

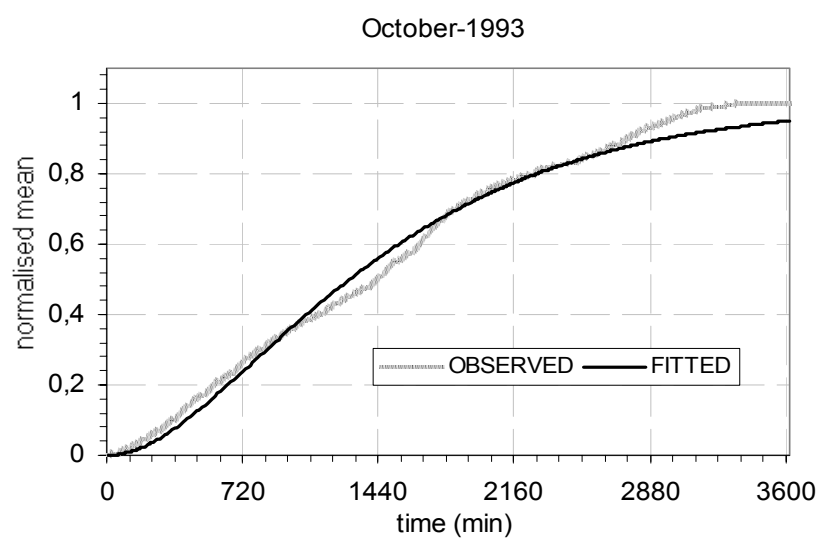

Fig. 5. Normalised mean function - October 1993 event.

For practical purposes, a value of $\alpha$ is selected so that it minimizes the sum of the mean square error about the previous function describing the autocorrelation over the course of the storm. Therefore, it is possible to obtain an estimate for $\alpha$ through Eq. (40), when comparing fitted with the corresponding computed empirical values. This equation can be also used conveniently in combination with Eq. (39) to provide estimates of $\beta$ and $\alpha$.

Concerning parameter $\varphi$, which defines gamma-type rain cells, it can be obtained directly from the relationship: $\varphi=$ $\alpha e$.

As an example, Fig. 4 shows the autocorrelation of the averaged process for the case of the event that occurred in October 1993. Lags are ranging from $10 \mathrm{~min}$ to $1 \mathrm{~h}$.

The estimated value of $\alpha$ is $0.026 \mathrm{~min}^{-1}$ or $\alpha^{-1}=$ $38.5 \mathrm{~min}$., and the corresponding value derived for $\varphi$ is $0.071 \mathrm{~min}^{-1}$.

\subsubsection{Estimation of $\beta$ and $n$ parameters}

Values of $n$ and $\beta$ are estimated to minimize the sum of the mean square error about the function describing the normalized mean depth over the course of the storm, when compared to the empirically computed curve for a given storm (Fig. 5).

The parameters of the Erlang distribution for the selected example-event are $n=1, \beta=0.0013$, and the corresponding mean value of cell's birth process is $\frac{n+1}{\beta}=1549.6 \mathrm{~min}$.

\subsection{Mean cell center intensity}

The parameter $E\left[i_{0}\right]$ mainly controls the magnitude of the storm event. The mean initial cell center intensity $E\left[i_{0}\right]$ for any storm may be expressed as a function of $\alpha$ and the mean of the total storm depth.

From Eq. (17), $E\left[i_{0}\right]$ is:

$$
E\left[i_{0}\right]=\frac{\alpha}{2 \pi \lambda E\left[D^{2}\right]} E[h(\infty, z)]
$$


Table 2. Summary of parameter estimates

\begin{tabular}{|c|c|c|c|c|c|c|c|}
\hline & $\delta$ & $\theta$ & $\lambda$ cells $/ \mathrm{km}^{2}$ & $E\left[i_{0}\right] \mathrm{mm} \mathrm{min}^{-1}$ & $\alpha \min ^{-1}$ & $\beta \min ^{-1}$ & $n$ \\
\hline 1 January 1991 & 2.24 & 99.20 & $3.83 \mathrm{E}-03$ & 0.50 & $2.54 \mathrm{E}-02$ & 2.93E-03 & 2 \\
\hline 2 January 1991 & 1.56 & 21.00 & $5.11 \mathrm{E}-03$ & 0.68 & $1.66 \mathrm{E}-02$ & $1.09 \mathrm{E}-03$ & 1 \\
\hline 1 February 1993 & 1.31 & 4.23 & $1.66 \mathrm{E}-02$ & 1.23 & $2.61 \mathrm{E}-02$ & $2.36 \mathrm{E}-03$ & 4 \\
\hline 2 February 1993 & 1.54 & 3.54 & $5.31 \mathrm{E}-02$ & 0.63 & $5.20 \mathrm{E}-02$ & $2.52 \mathrm{E}-03$ & 3 \\
\hline 1 April 1991 & 7.27 & 200.00 & $9.39 \mathrm{E}-03$ & 0.30 & 2.89E-02 & $5.84 \mathrm{E}-03$ & 4 \\
\hline 2 April 1991 & 3.00 & 50.00 & $1.48 \mathrm{E}-02$ & 0.70 & $5.70 \mathrm{E}-02$ & $1.44 \mathrm{E}-02$ & 9 \\
\hline May 1992 & 1.26 & 3.27 & $9.35 \mathrm{E}-03$ & 1.50 & $1.60 \mathrm{E}-02$ & $1.91 \mathrm{E}-03$ & 1 \\
\hline 1 June 1992 & 1.22 & 0.25 & $3.17 \mathrm{E}-01$ & 0.50 & $5.02 \mathrm{E}-02$ & $1.04 \mathrm{E}-02$ & 6 \\
\hline 2 June 1992 & 1.28 & 1.10 & $9.01 \mathrm{E}-02$ & 0.80 & $6.04 \mathrm{E}-02$ & $5.72 \mathrm{E}-03$ & 1 \\
\hline June 1993 & 1.50 & 6.36 & $1.00 \mathrm{E}-02$ & 0.90 & $7.25 \mathrm{E}-02$ & 4.62E-02 & 8 \\
\hline July 1993 & 2.43 & 28.55 & $4.30 \mathrm{E}-03$ & 1.90 & $5.45 \mathrm{E}-02$ & $3.81 \mathrm{E}-02$ & 8 \\
\hline August 1996 & 1.28 & 0.54 & $8.14 \mathrm{E}-02$ & 1.10 & $8.26 \mathrm{E}-02$ & $1.22 \mathrm{E}-02$ & 2 \\
\hline September 1991 & 12.00 & 32.62 & 7.49E-02 & 0.75 & 7.95E-02 & $2.87 \mathrm{E}-02$ & 8 \\
\hline September 1992 & 1.69 & 5.62 & $3.49 \mathrm{E}-02$ & 0.60 & 7.71E-02 & $1.62 \mathrm{E}-02$ & 4 \\
\hline 1 September 1994 & 2.18 & 2.00 & $1.30 \mathrm{E}-01$ & 1.13 & $5.70 \mathrm{E}-02$ & $2.24 \mathrm{E}-02$ & 8 \\
\hline 2 September 1994 & 1.72 & 22.1 & $1.62 \mathrm{E}-02$ & 0.90 & 7.10E-02 & $9.51 \mathrm{E} 03$ & 7 \\
\hline September 1996 & 1.56 & 18.65 & $3.81 \mathrm{E}-03$ & 2.36 & $2.50 \mathrm{E}-02$ & $2.96 \mathrm{E}-03$ & 4 \\
\hline 1 September 1997 & 3.01 & 55.35 & $5.69 \mathrm{E}-03$ & 0.80 & 7.13E-02 & $2.73 \mathrm{E}-02$ & 6 \\
\hline 2 September 1997 & 3.11 & 51.01 & $3.08 \mathrm{E}-03$ & 1.30 & $2.42 \mathrm{E}-02$ & $4.15 \mathrm{E}-03$ & 0 \\
\hline 3 September 1997 & 1.71 & 41.41 & $3.11 \mathrm{E}-03$ & 1.87 & $2.96 \mathrm{E}-02$ & $6.86 \mathrm{E}-03$ & 3 \\
\hline October 1991 & 5.52 & 12.64 & $3.06 \mathrm{E}-02$ & 1.80 & 2.31E-02 & $5.46 \mathrm{E}-03$ & 2 \\
\hline October 1992 & 1.97 & 27.56 & $4.21 \mathrm{E}-03$ & 1.20 & $2.38 \mathrm{E}-02$ & $4.81 \mathrm{E}-03$ & 3 \\
\hline October 1993 & 1.70 & 6.44 & $2.09 \mathrm{E}-02$ & 1.53 & $2.62 \mathrm{E}-02$ & $1.30 \mathrm{E}-03$ & 1 \\
\hline 1 October 1994 & 2.08 & 48.00 & $4.02 \mathrm{E}-03$ & 0.90 & $5.24 \mathrm{E}-02$ & $7.41 \mathrm{E}-03$ & 2 \\
\hline 2 October 1994 & 1.55 & 31.16 & 7.93E-03 & 1.12 & $5.85 \mathrm{E}-02$ & 7.79E-03 & 5 \\
\hline 3 October 1994 & 1.90 & 3.16 & $4.06 \mathrm{E}-02$ & 1.40 & $2.66 \mathrm{E}-02$ & $3.40 \mathrm{E}-03$ & 1 \\
\hline November 1993 & 1.40 & 0.56 & $3.68 \mathrm{E}-01$ & 0.46 & $6.13 \mathrm{E}-02$ & $7.66 \mathrm{E}-03$ & 4 \\
\hline Dicember 1992 & 1.67 & 20.36 & $1.14 \mathrm{E}-02$ & 0.80 & $2.26 \mathrm{E}-02$ & $6.76 \mathrm{E}-04$ & 1 \\
\hline Dicember 1997 & 1.22 & 0.28 & $1.28 \mathrm{E}-01$ & 0.50 & $2.63 \mathrm{E}-02$ & $3.42 \mathrm{E}-03$ & 3 \\
\hline October 1900 & 1.42 & 27.06 & $6.8 \mathrm{E}-03$ & 2.70 & $3.50 \mathrm{E}-02$ & $1.2 \mathrm{E}-03$ & 2 \\
\hline
\end{tabular}

This equation allows a direct estimation of $E\left[i_{0}\right]$, yielding the value $E\left[i_{0}\right]=1.53 \mathrm{~mm} \mathrm{~d}^{-1}$ for the October 1993 storm under consideration.

\subsection{Summary of parameter estimates}

The parameter estimation procedure has been applied to the complete sample of 30 rainfall events, resulting in a set of parameters which is summarized in Table 2.

It should be outlined that in all cases the procedure successfully yielded to a set of values for the model parameters which can be regarded as physically consistent, belonging to ranges of variation that clearly correspond to the conceptual building assumptions of the theoretical models presented herein.

On the other hand, the feasibility of the proposed parameter estimation procedure has been successfully tested through the application to the sample of storms under consideration, which can reasonably be considered a good representation of typical convective rainfall events in the Mediterranean regions of Spain.

\section{Summary and conclusions}

This paper presents a multidimensional, non-stationary space-time rainfall model for a single storm event of convective nature. The model conceptualizes the storm as a set of rain cells which are born in space and time following a Poisson process. Functional expressions with random parameters are used to describe the evolution of the rainfall cells, along the lines proposed by Rodriguez-Iturbe and Eagleson (1987), who demonstrated that modeling the spatial and temporal structure of rainstorms events through mathematical multidimensional point process techniques is feasible in practice.

When trying to apply their model to convective rainfall events recorded in the Spanish Mediterranean coast, it was found that some of the theoretical expressions that are needed to estimate the model parameters did not properly fit the observed values.

Based on the original formulation of Rodriguez-Iturbe and Eagleson (1987), a new model has been derived:

- The birth rate function has been improved. An Erlang distribution with parameters $\beta$ and $\mathrm{n}$ was used (an exponential distribution is obtained when $n=0$, as in the 
Rodriguez-Iturbe and Eagleson work). The estimated $n$ values in 28 out of 30 selected events have been found to be greater than zero.

- A gamma function mimics the growing, maturing and gradual decay of the raincell intensity (in the work by Rodriguez-Iturbe and Eagleson (1987) an exponential function was used). Times to the maximum of the estimated gamma function range from $4.5 \mathrm{~min}$ to $23 \mathrm{~min}$.

The mean, variance and covariance expressions of the rainfall intensity process $\xi(t, z)$ and the cumulative depth of rainfall process $h(T, z)$ have been obtained.

For 30 events, parameters were estimated based on the method of moments. Temporal parameters have been estimated (especially $\alpha$ parameter) applying a different strategy from that used in Jacobs et al. (1988). Expressions of the temporally averaged process have been used. Values obtained for $\alpha$ fall in the interval $(0.016 ; 0.083) \mathrm{min}^{-1}$, being $1 / \alpha$ directly related to the order of magnitud of cell's duration, with an average of $0.4 \mathrm{~h}$, slightly lower than the duration scale indicator of $0.7 \mathrm{~h}$ reported by Waymire (1984), or the $0.75 \mathrm{~h}$ value reported by Yoo et al. (1996). It is interesting to note that in the results obtained, $40 \%$ of the storms have values of $1 / \alpha$ in the interval $(0.56 \mathrm{~h}, 0.74 \mathrm{~h})$, mainly corresponding to events ocurred in September and October, while other values associated with cells of lower durations are identified mainly in summer events (June-August), with an average value $1 / \alpha=0.26 \mathrm{~h}$. Such results are consistent with the specific dynamics characterizing the summer rainstorms in the mediterranean region under study, involving the occurrence of very localized and extremely short duration raincells (Llasat, 2001). Values obtained for $E\left[i_{0}\right]$ are also consistent, almost coincident, with previous results reported in the literature. The average value over the ensemble of storms is $66 \mathrm{~mm} / \mathrm{h}$, while Waymire (1984) reports a value of $60 \mathrm{~mm} / \mathrm{h}$ in the summary of typical ranges of various parameters, and Valdés et al. (1990) report values ranging from 20 to $80 \mathrm{~mm} / \mathrm{h}$, with an average of $57 \mathrm{~mm} / \mathrm{h}$. The rest of the parameters are also found to be consistent with the typical ranges used by different authors (Valdés et al., 1990; Jacobs et al., 1988).

$\lambda$ parameter controls the spatial density of cells. An average value of 0.05 cells $/ \mathrm{km}^{2}$ has been estimated, comparable to other values reported previously $\left(0.016 \mathrm{cells} / \mathrm{km}^{2}\right.$, in Waymire et al., 1984; or 0.075 cells $/ \mathrm{km}^{2}$ in Jacobs et al., 1988). It should be outlined, though, that $\lambda$ varies significantly from one storm to another, not being a clear relationship in this case with possible seasonal variations. It should be noted that estimation of such parameter depends on the selection of the geographical area covered by the storm, which in many cases is necessarily affected by a degree of subjectivity. This parameter sensitivity to storm size should be investigated.

Both of the models and corresponding parameter estimation strategies proposed herein can be applied with larger data sets and denser networks, through the steps presented in the application of this research. This suggests that finer resolution data obtained from either denser land- networks or from meteorological radar rainfall estimates will improve model operation and reliability as a numerical simulator of realistic space-time rainfall intensity fields. More applied numerical experiments with the model are required to evaluate the practical benefits that can be expected from its used in applied hydrology, being clear to the authors that the greatest potentials are oriented towards watershed management and modeling with the aid of hydrological distributed simulation models that incorporate rainfall generators of this kind, adequately adapted to the characteristic rainfall events and their features occurring in the geographical region under study. In particular, the model reported herein with gamma-type raincells, in connection with a rainfall-runoff model, has already been used for reservoir management purposes in Spain, by means of synthetic generation of inflow hydrographs of large return period, assessing the evaluation of flood control operational criteria in the Beniarrés dam (South East of Spain). (Garcia-Bartual and Serra, 2001; Garcia-Bartual et al., 2002).

Acknowledgements. This research was supported by the European Commission Environment and Climate Research Programme through the FRAMEWORK Project (Contract No. ENV4-CT970529). The authors thank S.A.I.H.-Confederación Hidrográfica del Júcar (Valencia, Spain) for providing the rainfall data.

\section{References}

Bartolini, P. and Valdés, J. B.: Representation of spatial variability of rainfall in aggregated rainfal-runoff models, ASCE Journal of Hydraulic Engineering 120, 10, 1199-1219, 1994.

Garcia-Bartual, R., Albentosa, E., Paciarotti, J., and Utrillas, R. J. L.: Simulación hidrológica de escenarios de crecida con el modelo RAINGEN para asesoramiento en la elaboración de normas de explotación de embalses. VII Jornadas Españolas de Presas - Comité Nacional Español de Grandes Presas. Zaragoza (Spain). Vol. III, 195-205. 2002.

Garcia-Bartual, R. and Marco, J.: A stochastic model of the internal structure of convective precipitation in time at a raingauge site, J. of Hydrology, 118, 129-142, 1990.

Garcia-Bartual and Serra, F.: Performance of a multidimensional rainfall model for simulation purposes, XXXII Annual Conference-AIRO 2001, Operational Research in land and resources management, Villasimius - Cagliari (ITALIA), 4-7 Sept., 2001.

Hershfield, D. M.: Some statistical properties of short-duration rainfall, Water Science and Technology, 16, 8/9, 93-100, 1984.

Islam, S., Bras, R. L., and Rodriguez-Iturbe, I.: Multidimensional modeling of cumulative rainfall: Parameter estimation and model adequacy through a continuum of scales, Water Resour. Res., 24, 7, 985-992, 1988.

Jacobs, L. B., Rodriguez-Iturbe, I., and Eagleson, P. S.: Evaluation of a homogeneous point process description of Arizona thunderstorm rainfall, Water Resour. Res., 24, 7, 1174-1186, 1988.

Lázaro, C. and Garcia-Bartual, R.: Estimation of multidimensional precipitation parameters from the automatic hydrological information system (SAIH) data at eastern Spain, Proceedings of the XXIV International Association for Hydraulic Research Congress, Madrid, A.1-A.10, 1991. 
Llasat, M. C.: An objective classification of rainfall events on the basis of their convective features: application to rainfall intensity in the Northeast of Spain, Inter. Jour. of Climatology, 21, 13851400. 2001.

Luyckx, G., Willems, P., and Berlamont, J.: Influence of the spatial variability of rainfall on sewer system design, in: Hydrology in a changing environment, (Eds) Wheater, H. and Kirby, C., Wheather, Wiley, Chichester, 3, 339-349, 1998.

Northrop, P.: A clustered spatial-temporal model of rainfall, Proceedings of the Royal Society of London, Series A 454, 18751888, 1998.

Orlanski, I.: A rational subdivision of scales for atmospheric processes, Bull. Am. Meteorol. Soc., 52, 1186-1188, 1975.

Rodriguez-Iturbe, I. and Eagleson, P. S.: Mathematical models of rainstorm events in space and time, Water Resources Research, 23, 1, 181-190, 1987.

Sivapalan, M. and Wood, E. F.: A multidimensional model of non stationary space-time rainfall at the catchment scale, Water Resources Research, 23, 7, 1289-1299, 1987.
U.S. Department of Agriculture Soil Conservation Service, Urban hydrology for small watersheds, tech. release No. 55, June 1986.

Valdés, J. B., Nakamoto, S., Shen, S. S. P., and North, G. R.: Estimation of multidimensional precipitation parameters by areal estimates of oceanic rainfall, J. of Geophysical Reseach, 95, D3, 2101-2111, 1990.

Vanmarcke, E.: Random fields: Analysis and Synthesis, MIT Press, Cambridge, Mass., 1983.

Waymire, E., Gupta, V. K., and Rodriguez-Iturbe, I.: A Spectral Theory of Rainfall Intensity at the Meso- $\beta$ scale, Water Resour. Res., 20, 10, 1453-1465, 1984.

Willems, P.: Stochastic generation of spatial rainfall for urban areas, Water Science and Technology, 39, 9, 23-30, 1999.

Willems, P.: A spatial rainfall generator for small spatial scales, J. of Hydrology, 252, 126-144, 2001.

Yoo, C., Valdés, J. B., and North, G. R.: Stochastic modeling of multidimensional precipitation fields considering spectral structure, Water Resour. Res., 32, 7, 2175-2187, 1996. 